\title{
MODO DE REPRODUÇÃO E VIABILIDADE DE PÓLEN DE TRÊS ESPÉCIES DE JABUTICABEIRA ${ }^{1}$
}

\author{
MOESES ANDRIGO DANNER ${ }^{2}$, IDEMIR CITADIN³, SIMONE APARECIDA ZOLET SASSO 3 , \\ MARCOS ROBSON SACHET ${ }^{4}$, GUSTAVO MALAGI ${ }^{5}$
}

RESUMO - O objetivo deste trabalho foi determinar o modo de reprodução e as condições para testes de viabilidade in vitro de pólen de três espécies de jabuticabeira (Plinia cauliflora, P. trunciflora e P. jaboti$c a b a$ ). Avaliaram-se a frutificação efetiva em ramos ensacados e não ensacados, e aspectos da morfologia floral. A viabilidade de pólen foi avaliada em meio de cultura com e sem ácido bórico, com pólen coletado em diferentes períodos após antese. A germinação de pólen de seis genótipos foi quantificada antes e após armazenamento. P. trunciflora e P. jaboticaba são autocompatíveis, porém os polinizadores aumentam a frutificação. A espécie Plinia cauliflora necessita de agentes polinizadores para frutificar, pois apresenta flores com maior distância estigma-anteras que as outras duas espécies, o que impede a autofecundação passiva. A adição de ácido bórico no meio de cultura aumenta a germinação in vitro de pólen de jabuticabeira. A viabilidade do pólen é máxima após seis horas da antese. É possível a conservação do pólen por até 90 dias em congelador $\left(-18^{\circ} \mathrm{C}\right)$, desde que apresente alta germinação inicial (maior que $80 \%$ ). Esses resultados auxiliam no planejamento de cruzamentos em jabuticabeira.

Termos para indexação: Plinia sp., polinização, armazenamento de pólen, boro.

\section{REPRODUCTIVE MODE AND POLLEN VIABILITY OF THREE JABUTICABA TREE SPECIES}

\begin{abstract}
The objective of this study was to determine the reproductive mode and the conditions for in vitro pollen viability testing of three jabuticaba tree species (Plinia cauliflora, P. trunciflora and P. jaboticaba). Observed fruit set in bagged and not bagged branches and aspects of floral morphology. Pollen viability was evaluated in culture medium with and without boric acid with pollen collected at different times after anthesis. Pollen germination of six genotypes was quantified before and after storage. P. trunciflora and $P$. jaboticaba are self-compatible, however the polinizer increase fruiting. The $P$. cauliflora requires polinizers for fruiting, because it has flowers with greater stigma-anther distance than the other two species, which prevents the passive self-pollination. Boric acid ads in the culture medium improve in vitro germination of jabuticaba tree pollen. The pollen viability is greater six hours after anthesis. It is possible the conservation of pollen for up to 90 days in freezer $\left(-18^{\circ} \mathrm{C}\right)$, if it has high initial germination (greater than $80 \%$ ). These results will help in planning crosses in jabutica tree.
\end{abstract}

Index terms: Plinia sp., pollination, pollen storage, boron.

\footnotetext{
${ }_{1}$ (Trabalho 124-10). Recebido em: 11-05-2010. Aceito para publicação em: 03-09-2010.

${ }^{2}$ Eng. Agr. MSc. Programa de Pós-Graduação em Agronomia. UTFPR, Câmpus Pato Branco.E-mails: moesesandrigo@yahoo.com.br; iosasso@ibest.com.br

${ }^{3}$ Eng. Agr. Dr. Professor Programa de Pós-Graduação em Agronomia. UTFPR, Câmpus Pato Branco. idemir@utfpr.edu.br ${ }^{4}$ Acadêmico de Agronomia. UTFPR, Câmpus Pato Branco. marcos.sachet@gmail.com

${ }^{5}$ Eng. Agr. Mestrando. Programa de Pós-Graduação em Agronomia. UTFPR, Câmpus Pato Branco. malagi@agronomo.eng.br
} 


\section{INTRODUÇÃO}

A jabuticabeira (Plinia sp.) é originária do centro/sul/sudeste do Brasil e pertence à família Myrtaceae. São conhecidas nove espécies de jabuticabeira e dentre elas destacam-se $P$. trunciflora Berg, conhecida como jabuticaba de cabinho; $P$. cauliflora (DC) Berg, conhecida como jabuticaba paulista ou jabuticaba-açu; e P. jaboticaba (Vell.) Berg, conhecida como jabuticaba Sabará, a espécie mais comercializada no Brasil (MATTOS, 1983).

Além do interesse pelo consumo dos frutos, existe o interesse da indústria farmacêutica e alimentícia, pois essa fruteira contém alto teor de óleos essenciais nas folhas (APEL et al., 2006) e antocianinas na casca do fruto (TEIXEIRA et al., 2008).

O conhecimento do sistema de reprodução de uma espécie é importante para a conservação do germoplasma, o manejo em cultivo e para o melhoramento genético, pois permite definir estratégias de seleção com base em cruzamentos intra e interpopulacionais. As flores de jabuticabeira são hermafroditas, com potencial para autopolinização. Porém, o modo de reprodução da espécie é um aspecto ainda pouco estudado.

$\mathrm{O}$ estudo das condições de germinação in vitro e de armazenamento do pólen de uma espécie também é importante em programas de melhoramento genético, pois permitem obter maior sucesso nos cruzamentos. Até o momento, não são conhecidas as condições adequadas para testes de germinação in vitro e conservação do pólen de jabuticabeira. Com relação a outras fruteiras da família Myrtaceae, nativas do Sul do Brasil, foram encontrados na literatura estudos com viabilidade de pólen de cerejeira-domato, Eugenia involucrata (FRANZON; RASEIRA, 2006) e pitangueira, Eugenia uniflora (FRANZON et al., 2007), demonstrando algumas condições necessárias para a conservação de pólen dessas espécies.

O objetivo deste trabalho foi determinar o modo de reprodução e as condições para testes de viabilidade in vitro de pólen de três espécies de jabuticabeira (Plinia cauliflora, P. trunciflora e $P$. jaboticaba).

\section{MATERIAL E MÉTODOS}

\section{Modo de reprodução}

Foram utilizadas seis plantas (genótipos) de jabuticabeira, localizadas em Itapejara D'Oeste-PR (2557'34” S; 5248'54” W; 518 m de altitude). Em agosto de 2008, foram marcados nove ramos por planta e aplicados, em cada grupo de três ramos, os seguintes tratamentos: T1 - ramos não ensacados, para observar a frutificação em polinização livre; T2 - ramos ensacados com tela antiafídeo (tecido voal), para evitar a polinização por insetos; T3 - ramos ensacados com TNT (tecido não tecido), para evitar a polinização por insetos e por vento. Inicialmente, realizaram-se a contagem do número de gemas florais e, após 30 dias da antese, a observação da frutificação efetiva nos ramos ensacados e não ensacados.

$\mathrm{O}$ experimento foi conduzido no delineamento inteiramente casualizado, com três repetições (ramos), em esquema fatorial $3 \times 6$, sendo três formas de proteção do ramo e seis genótipos de jabuticabeira (Plinia cauliflora 1, P. cauliflora 4, P. trunciflora 1, P. trunciflora 3, P. trunciflora 4 e P. jaboticaba 1).

Em 2009, este experimento foi repetido nas mesmas condições anteriores e, adicionalmente, foram efetuadas medições de diâmetro de abertura da corola (logo após a antese), distância estigmaanteras, comprimento do pistilo e contado o número de anteras em 20 flores de cada um dos genótipos. Os dados foram avaliados utilizando estatística descritiva (média e desvio-padrão).

Os valores de percentual de frutificação efetiva foram submetidos à análise de variância, seguida pelo agrupamento de médias, pelo teste de Scott-Knott $(P \leq 0,05)$, utilizando o programa Genes (CRUZ, 2006).

\section{Viabilidade de pólen}

A viabilidade de pólen de jabuticabeira foi testada em dois experimentos, utilizando pólen coletado de plantas localizadas em Itapejara D'Oeste-PR. No primeiro experimento, testou-se a viabilidade de pólen em função do período após abertura da flor. Para isso, utilizou-se pólen coletado do genótipo Plinia cauliflora 4, em agosto de 2008. Retiraramse ramos da planta no campo, contendo flores em estádio de balão, os quais foram transportados para o laboratório e deixados em frascos com água até a abertura da flor. A partir daí, foram coletadas anteras das flores em cinco períodos: logo após a antese, $3 ; 6$; 12 e 24 horas após a antese. As anteras foram destacadas com pinça e colocadas para secar em bandejas de papel, em local seco, à temperatura ambiente (20 a $25^{\circ} \mathrm{C}$ ), por 72 horas.

Foram testados dois meios de cultura: (1) $10 \%$ de sacarose $+1 \%$ de ágar; (2) $10 \%$ de sacarose $+1 \%$ de ágar $+2,0 \mathrm{mM}$ de ácido bórico $\left(\mathrm{H}_{3} \mathrm{BO}_{3}\right)$. Os elementos componentes do meio de cultura foram misturados e dissolvidos em água destilada, sendo aquecidos em forno micro-ondas até completa dissolução do ágar. O meio ainda quente foi, então, colocado em lâminas, contendo dois anéis de PVC de $21 \mathrm{~mm}$ de diâmetro e $3 \mathrm{~mm}$ de altura, adaptação 
esta que substitui a lâmina escavada. Após o meio de cultura esfriar, o pólen foi aspergido sobre o meio. As lâminas foram colocadas em placas de Petri contendo papel umedecido (câmara úmida) e incubadas em estufa tipo B.O.D. a $25^{\circ} \mathrm{C}$, durante sete horas, na ausência de luz.

A contagem dos grãos de pólen germinados (que emitiram o tubo polínico) foi efetuada com auxílio de microscópio óptico, observando-se duas amostras de 100 grãos de pólen por lâmina, compondo a unidade experimental. O delineamento empregado foi o inteiramente casualizado, com quatro repetições. Utilizou-se esquema fatorial 5 × 2, sendo cinco períodos de coleta das anteras e dois meios de cultura para germinação in vitro do pólen.

No segundo experimento, testou-se a viabilidade do pólen, coletado em agosto de 2008, de seis plantas (genótipos) de jabuticabeira, localizadas no município de Itapejara D’Oeste-PR, em função do período de armazenamento do pólen. Coletaram-se ramos de cada planta, contendo flores em estádio de balão, os quais foram transportados para o laboratório e deixados em frascos com água até a abertura da flor. Após seis horas da abertura da flor, foram retiradas as anteras e colocadas para secar nas mesmas condições que o experimento anterior. $\mathrm{O}$ pólen foi então colocado em frascos de vidro. Uma amostra desse pólen foi submetida à germinação inicial (sem armazenamento). Os frascos com pólen foram acondicionados dentro de um dessecador contendo sílica gel (como substância higroscópica) e armazenados em congelador $\left(-18^{\circ} \mathrm{C}\right)$.

Para a germinação de pólen in vitro, utilizouse o meio de cultura constituído por $10 \%$ de sacarose $+1 \%$ de ágar $+2,0 \mathrm{mM}$ de $\mathrm{H}_{3} \mathrm{BO}_{3}$. As condições para o preparo do meio, incubação do pólen e contagem dos grãos de pólen germinados foram iguais ao experimento anterior.

O delineamento experimental empregado foi o inteiramente casualizado, com quatro repetições. Utilizou-se esquema fatorial $6 \times 5$, sendo seis genótipos (Plinia cauliflora 1, P. cauliflora 4, P. trunciflora 1, P. trunciflora 3, P. trunciflora 4 e P. jaboticaba 1$)$ e cinco períodos de armazenamento do pólen $(0 ; 30$; 60; 90 e 120 dias). Os dados dos dois experimentos foram avaliados utilizando estatística descritiva (média e desvio-padrão).

\section{RESULTADOS E DISCUSSÃO}

\section{Modo de reprodução}

Para todos os genótipos, a frutificação efetiva foi significativamente maior em ramos de polinização livre (sem ensacamento), com média de
$28,4 \%$ e $25,4 \%$, em relação àqueles ensacados com tela antiafídeo $(5,8 \%$ e $11 \%)$ e ensacados com TNT (4,0\% e 6,1\%), em 2008 e 2009, respectivamente. Em 2008, em ramos de polinização livre de Plinia trunciflora 3, houve elevada frutificação efetiva $(58,4 \%)$, bem superior aos demais genótipos, o que demonstra a elevada capacidade produtiva dessa planta (Tabela 1).

Os genótipos da espécie Plinia cauliflora apresentaram menor frutificação efetiva em ramos de polinização livre, em relação aos demais genótipos, com média dos dois genótipos ( $P$. cauliflora 1 e $P$. cauliflora 4 ) de $4,9 \%$ e $8,9 \%$, em 2008 e 2009 , respectivamente. A baixa frutificação efetiva dessas plantas não representa baixa produção, pois as plantas são de grande porte (de 5 a $7 \mathrm{~m}$ de altura) e apresentam elevado número de ramos produtivos, e a produção estimada de frutos por planta foi de $70 \mathrm{~kg}$.

Os genótipos da espécie Plinia cauliflora não apresentaram frutificação em ramos ensacados, ao contrário dos outros genótipos. O fato de ocorrer frutificação em ramos ensacados das espécies Plinia trunciflora e Plinia jaboticaba indica que estas espécies são autocompatíveis. Entretanto, para uma efetiva polinização, são necessários agentes polinizadores (as abelhas), visto que os ramos não ensacados tiveram frutificação bem superior aos ramos ensacados. A necessidade de polinizadores para aumentar a produção de frutos foi observada também em goiabeira, Psidium guajava, outra fruteira da família Myrtaceae (ALVES; FREITAS, 2007).

Provavelmente, a espécie Plinia cauliflora também é autocompatível, apesar de não ter sido observada frutificação em ramos ensacados. Algumas hipóteses podem ser geradas para explicar este fato. Uma delas diz respeito à deficiência na polinização devido à morfologia floral. Observou-se que, nas flores de Plinia cauliflora, as anteras localizam-se mais distantes do estigma em relação às outras duas espécies (Tabela 2), o que pode estar impedindo a autopolinização passiva. Nas espécies Plinia trunciflora e Plinia jaboticaba, esta distância é menor, e o contato entre o pólen e o estigma da mesma flor é facilitado. As plantas Plinia trunciflora 1 e Plinia jaboticaba 1 apresentam menores dimensões (menor diâmetro de abertura da corola, menor comprimento do pistilo e menor número de anteras) que os demais genótipos. Seus frutos também são menores.

Assim, para possibilitar a frutificação na espécie Plinia cauliflora, foi necessária a ação de insetos, para efetuar o contato do pólen sobre o estigma da mesma flor (autofecundação) ou de outras flores (polinização cruzada). Nesse sentido, Degenhardt et 
al. (2001) verificaram, em clones autocompatíveis de goiabeira serrana (Acca sellowiana, Myrtaceae), que a característica floral de apresentar estigmas com menor distância em relação às anteras permitiu a autopolinização por entomofilia. Segundo MalerboSouza et al. (2004), os principais insetos polinizadores da jabuticabeira são as abelhas africanizadas (Apis mellifera), que coletam exclusivamente pólen, pois o néctar das flores apresenta baixo teor de açúcares solúveis.

Malerbo-Souza et al. (2004) observaram percentual de frutificação efetiva média de 19\% em Plinia cauliflora, o qual não diferiu entre gemas ensacadas e não ensacadas, demonstrando que a espécie é autocompatível, mostrando que a presença de abelhas não interferiu na produção. Esta última indicação diverge dos resultados encontrados no presente trabalho. Possivelmente, isso decorre de variação entre genótipos da mesma espécie, devido a diferenças na morfologia floral.

Em experimento semelhante, realizado com pitangueira (Eugenia uniflora, Myrtaceae), Franzon (2008) observou frutificação efetiva de $38,4 \%, 13,6 \%$ e $6,4 \%$ para ramos de polinização livre, ensacados com tela antiafídeo e ensacados com TNT, respectivamente. $\mathrm{O}$ autor classificou a espécie como autocompatível, mas que necessita da atuação de agentes polinizadores, principalmente Apis mellifera, para melhor frutificação. Corroborando isso, Franzon et al. (2010) utilizaram marcadores moleculares AFLP para a avaliação de populações de plantas de pitangueira oriundas de autopolinização e de polinização livre, e os dados demonstraram que a espécie se reproduz tanto por autofertilização quanto por polinização cruzada. Porém, o nível de polimorfismo dentro das duas populações foi semelhante, o que pode ser indicativo de que a espécie efetua principalmente autopolinização.

No caso da jabuticabeira, outras características da espécie sugerem a reprodução por autogamia. A espécie apresenta padrão de floração em massa, denominado de big-bang, conforme observado também em outras espécies da família Myrtaceae (SILVA; PINHEIRO, 2007). Esta característica é uma estratégia de atração de polinizadores, desenvolvida por espécies autocompatíveis, que necessitam da ação destes para favorecer a autofertilização e, consequentemente, aumentar a taxa de frutificação (BEARDSELL et al., 1993), pois, além de atrair polinizadores, faz com que eles permaneçam mais tempo forrageando na mesma planta.

Porém, deve-se considerar que a produção de frutos de jabuticabeira pode ocorrer também por geitonogamia, ou seja, transferência de pólen entre flores da mesma planta pela ação do vento, insetos e/ ou gravidade, assim como ocorre em pitangueira (SILVA; PINHEIRO, 2007). Portanto, as duas estratégias de polinização (autopolinização e polinização por geitonogamia) parecem ser utilizadas pela espécie, o que é corroborado pelo fato de que jabuticabeiras cultivadas isoladamente apresentam frutificação normal.

Em alguns casos, diferenças na biologia floral entre espécies de mesmo gênero são identificadas. Por exemplo, Faria e Stehmann (2010) observaram que a espécie Passiflora pohlii é alógama e autoincompatível, enquanto Passiflora capsularis é autógama e autocompatível. Além disso, como em outras espécies, pode haver a possibilidade da presença de alelos de autoincompatibilidade (KODAD et al., 2009) e do desenvolvimento meiótico anormal, causando inviabilidade dos grãos de pólen e impossibilitando a autopolinização (FERREIRA et al., 2009).

Por isso, para confirmar a autocompatibilidade de $P$. cauliflora, sugere-se que sejam realizados estudos mais detalhados sobre sua biologia reprodutiva, como a autopolinização artificial de suas flores e a observação da fertilização in vivo, assim como a verificação do período de receptividade do estigma e o uso de marcadores genéticos codominantes (como os microssatélites), os quais podem fornecer maiores informações sobre os índices de polinização cruzada e de autopolinização da jabuticabeira.

\section{Viabilidade de pólen}

No primeiro experimento de viabilidade de pólen de jabuticabeira (Plinia cauliflora), o percentual de germinação in vitro foi maior utilizando o meio de cultura com ácido bórico $\left(\mathrm{H}_{3} \mathrm{BO}_{3}\right)$, em relação ao meio sem $\mathrm{H}_{3} \mathrm{BO}_{3}$. O percentual máximo de germinação foi obtido após seis horas da antese, sendo de $15 \%$ e $41 \%$ para os meios sem e com $\mathrm{H}_{3} \mathrm{BO}_{3}$, respectivamente (Figura 1).

Estes resultados evidenciam a necessidade de inclusão do $\mathrm{H}_{3} \mathrm{BO}_{3}$ no meio de cultura para a germinação in vitro de pólen de jabuticabeira. Ao contrário, $\mathrm{o}_{3} \mathrm{BO}_{3}$ é dispensável para a germinação in vitro de pólen de cerejeira-do-mato, Eugenia involucrata (FRANZON; RASEIRA, 2006) e pitangueira, Eugenia uniflora (FRANZON et al., 2007), ambas espécies da família Myrtaceae.

Observou-se que a abertura em massa das flores de jabuticabeira (tipo big-bang) ocorreu aproximadamente às $3 \mathrm{~h}$ da manhã. A viabilidade do pólen aumentou a partir daí e foi máxima às $9 \mathrm{~h}$ da manhã. Este horário coincide com o período de maior visitação pelas abelhas nas flores de jabuticabeira, conforme relatado por Malerbo-Souza et al. (2004) e também observado neste experimento. Este fato 
parece ser uma estratégia da planta para favorecer a polinização por estes vetores. Provavelmente, neste período, também o estigma deve estar receptivo, fator ainda a ser estudado, o que proporcionaria a autofertilização auxiliada pelas abelhas.

Resultados semelhantes foram encontrados para camu-camu (Myrciaria dubia, Myrtaceae), no qual a antese ocorreu das 5 às $7 \mathrm{~h}$ da manhã, e o pólen apresentou elevada viabilidade entre as 7 e $8 \mathrm{~h}$, coincidindo com a receptividade do estigma e visitação pelas abelhas (MAUÉS; COUTURIER, 2002).

No segundo experimento de viabilidade de pólen de jabuticabeira, observou-se que o percentual de germinação in vitro foi reduzido aproximadamente pela metade, após 30 dias de armazenamento a $-18^{\circ} \mathrm{C}$ e baixa umidade (dessecador contendo sílica gel). Isto ocorreu para todos os genótipos de Plinia trunciflora e Plinia jaboticaba. Os genótipos de Plinia cauliflora apresentaram menor germinação inicial e reduziram drasticamente a germinação após 30 dias de armazenamento (Figura 2), indicando que as condições testadas não são adequadas para o armazenamento do pólen dessa espécie.

A média da germinação inicial de pólen (sem armazenamento) foi de 54,5\%. Dessa forma, o pólen fresco apresentou condições de garantir alta eficiência (pegamento de frutos) se utilizado em cruzamentos, principalmente em se tratando dos genótipos Plinia trunciflora 1 (62\% de germinação), Plinia trunciflora 3 e Plinia trunciflora 4 (germinação > que 80\%). Porém, após 90 dias de armazenamento, apenas os genótipos Plinia trunciflora 3 e Plinia trunciflora 4 apresentaram razoável viabilidade $(31 \%$ e $25 \%$, respectivamente) e poderiam ser utilizados em hibridações. Porém, este fato é reflexo da alta germinação inicial do pólen destes dois genótipos, visto que a redução da germinação com o armazenamento foi proporcional à dos genótipos Plinia trunciflora $1 \mathrm{e}$ Plinia jaboticaba 1 .
Vale ressaltar que a floração de Plinia trunciflora 3 e Plinia trunciflora 4 ocorreu mais tardiamente ( 25 a 30 de agosto, temperatura média de $\left.17,8^{\circ} \mathrm{C}\right)$, em comparação à floração das plantas de Plinia cauliflora ( 8 a 15 de agosto, temperatura média de $16,9^{\circ} \mathrm{C}$ ). O período de floração mais tardio coincidiu com temperaturas mais altas, o que pode ter representado melhores condições para a formação e a viabilidade dos grãos de pólen.

As condições de armazenamento de pólen, normalmente utilizadas para outras fruteiras, parecem não ser as ideais para o pólen de fruteiras nativas da família Myrtaceae. Franzon et al. (2007) observaram que não é possível o armazenamento do pólen de pitangueira. Por outro lado, Franzon e Raseira (2006) verificaram que o pólen de cerejeirado-mato se conserva por até 220 dias, em condições semelhantes às utilizadas no presente experimento. No caso de outras espécies frutíferas, principalmente as de clima temperado, a conservação da viabilidade de pólen pode estender-se por até quatro anos (LEE et al., 1981).

Sugere-se que testes com armazenamento de pólen de jabuticabeira, por períodos maiores, sejam realizados utilizando o armazenamento em nitrogênio líquido, o qual se mostrou mais eficiente que o armazenamento em congelador $\left(-18^{\circ} \mathrm{C}\right)$ para viabilidade de pólen de cebola (Allium cepa) por dois anos (GOMES et al., 2003).

Os resultados deste trabalho podem auxiliar no planejamento de hibridações e no estabelecimento de programas de melhoramento genético da jabuticabeira. 
TABELA 1 - Frutificação efetiva (\%) em seis genótipos de jabuticabeira (Plinia sp.), submetidos aos tratamentos: polinização livre (sem ensacamento), ramos ensacados com tela antiafídeo e ramos ensacados com TNT, em 2008 e em 2009.

\begin{tabular}{|c|c|c|c|}
\hline Genótipos $^{1}$ & Polinização livre & Tela antiafídeo & TNT \\
\hline Plinia cauliflora 1 & $4,5 \mathrm{cA}$ & $0,0 \mathrm{cB}$ & $0,0 \mathrm{~dB}$ \\
\hline Plinia cauliflora 4 & $5,2 \mathrm{cA}$ & $0,0 \mathrm{cB}$ & $0,0 \mathrm{~dB}$ \\
\hline Plinia trunciflora 1 & $34,6 \mathrm{bA}$ & $5,4 \mathrm{bB}$ & $3,1 \mathrm{cC}$ \\
\hline Plinia trunciflora 3 & $58,4 \mathrm{aA}$ & $7,3 \mathrm{bB}$ & $5,0 \mathrm{bC}$ \\
\hline Plinia trunciflora 4 & $34,8 \mathrm{bA}$ & $15,7 \mathrm{aB}$ & $11,8 \mathrm{aC}$ \\
\hline Plinia jaboticaba 1 & $32,8 \mathrm{bA}$ & $6,5 \mathrm{bB}$ & $3,9 \mathrm{cC}$ \\
\hline Média & 28,4 & 5,8 & 4,0 \\
\hline CV (\%) & \multicolumn{3}{|c|}{6,5} \\
\hline Genótipos $^{2}$ & Polinização livre & Tela antiafídeo & TNT \\
\hline P. cauliflora 1 & $9,1 \mathrm{bA}$ & $0,0 \mathrm{~dB}$ & $0,0 \mathrm{~dB}$ \\
\hline P. cauliflora 4 & $8,7 \mathrm{bA}$ & $0,0 \mathrm{~dB}$ & $0,0 \mathrm{~dB}$ \\
\hline P. trunciflora 1 & $32,0 \mathrm{aA}$ & $18,1 \mathrm{bB}$ & $8,7 \mathrm{bC}$ \\
\hline P. trunciflora 3 & $33,7 \mathrm{aA}$ & $21,6 \mathrm{aB}$ & $11,5 \mathrm{aC}$ \\
\hline P. trunciflora 4 & $34,2 \mathrm{aA}$ & $15,9 \mathrm{bB}$ & $10,5 \mathrm{aC}$ \\
\hline P. jaboticaba 1 & $34,9 \mathrm{aA}$ & $10,3 \mathrm{cB}$ & $5,7 \mathrm{cC}$ \\
\hline Média & 25,4 & 11,0 & 6,1 \\
\hline $\mathrm{CV}(\%)$ & \multicolumn{3}{|c|}{9,6} \\
\hline
\end{tabular}

Médias seguidas de letras distintas, minúsculas na coluna e maiúsculas na linha, diferem entre si, pelo teste de $\operatorname{Scott}-\mathrm{Knott}(P \leq 0,05)$. ': avaliação em 2008. ${ }^{2}$ : avaliação em 2009.

TABELA 2 - Caracteres de flores de seis genótipos de jabuticabeira (Plinia sp.), avaliados em 2009.

\begin{tabular}{lcccr}
\hline \multicolumn{1}{c}{ Genótipos } & $\begin{array}{c}\text { Diâmetro de abertura } \\
\text { da corola }(\mathrm{mm})\end{array}$ & $\begin{array}{c}\text { Distância } \\
\text { estigma-anteras (mm) }\end{array}$ & Comprimento pistilo (mm) & $\mathrm{N}^{\circ}$ anteras \\
\hline P. cauliflora 1 & $16,0 \pm 2,3$ & $4,0 \pm 0,6$ & $10,2 \pm 1,1$ & $59,9 \pm 11,0$ \\
P. cauliflora 4 & $16,1 \pm 2,5$ & $4,1 \pm 0,5$ & $10,4 \pm 1,3$ & $59,3 \pm 9,7$ \\
P. trunciflora 1 & $9,4 \pm 1,2$ & $0,4 \pm 0,3$ & $6,1 \pm 1,1$ & $35,7 \pm 4,9$ \\
P. trunciflora 3 & $15,1 \pm 1,2$ & $0,9 \pm 0,3$ & $7,8 \pm 0,6$ & $53,2 \pm 10,6$ \\
P. trunciflora 4 & $15,0 \pm 1,1$ & $0,9 \pm 0,3$ & $7,9 \pm 0,7$ & $53,5 \pm 9,1$ \\
P. jaboticaba 1 & $11,0 \pm 1,4$ & $1,0 \pm 0,5$ & $7,6 \pm 0,8$ & $37,9 \pm 4,7$ \\
\hline
\end{tabular}

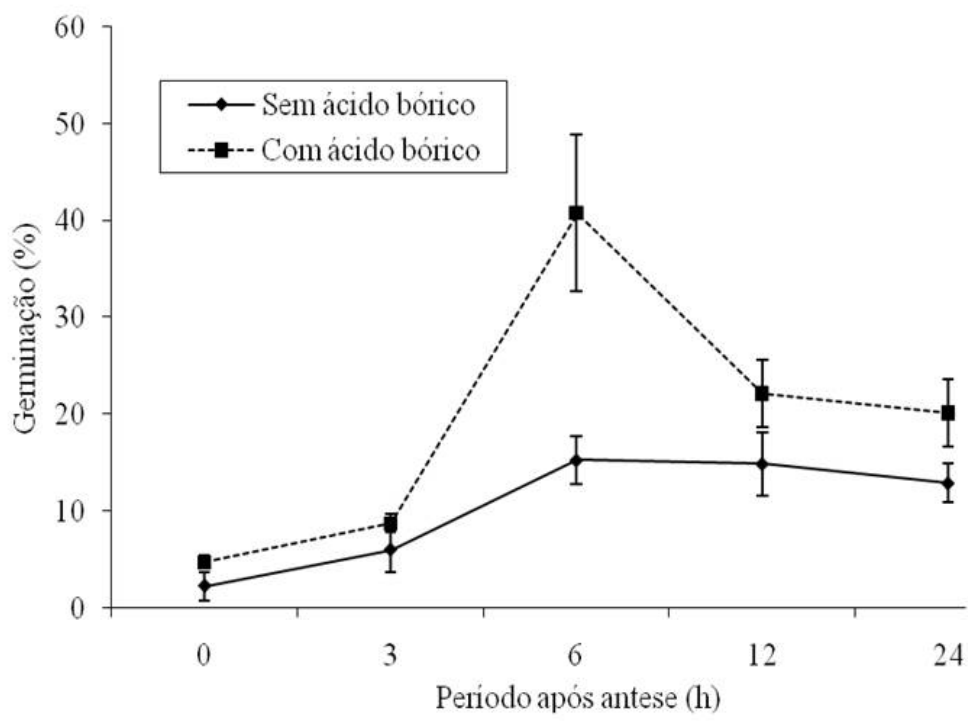

FIGURA 1 - Percentual de germinação in vitro de pólen de jabuticabeira (Plinia cauliflora), coletado em diferentes períodos após antese e em meio de cultura com e sem ácido bórico $\left(\mathrm{H}_{3} \mathrm{BO}_{3}\right)$. As barras representam o desvio-padrão. 


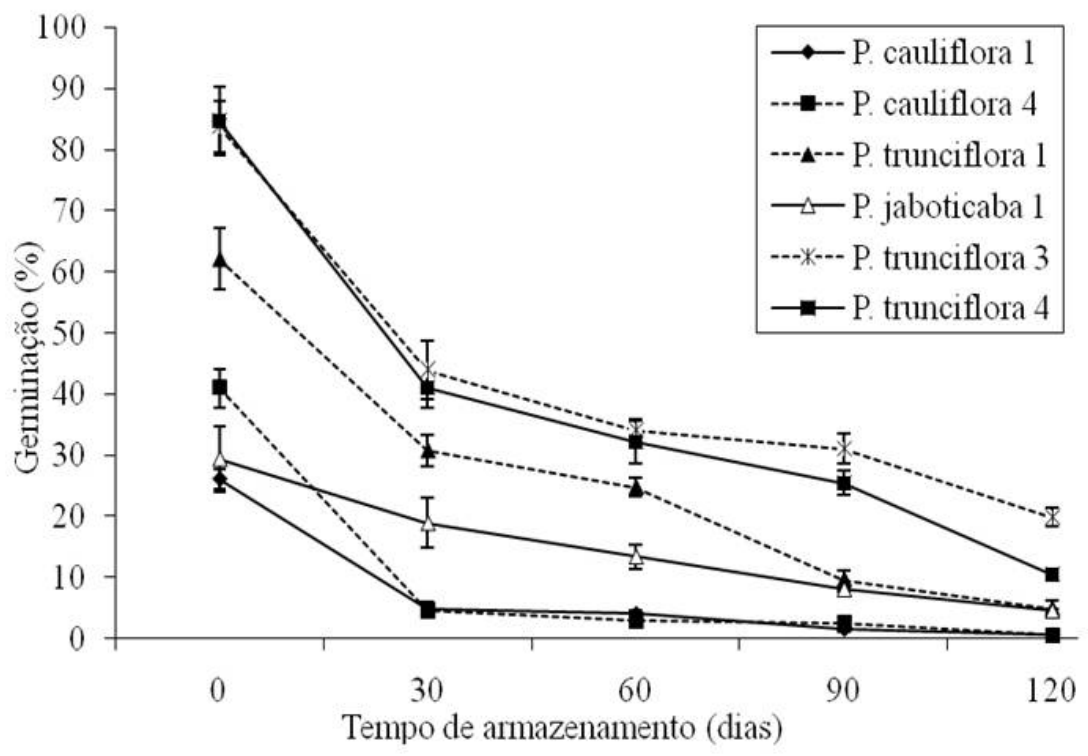

FIGURA 2 - Percentual de germinação in vitro de pólen de seis genótipos de jabuticabeira (Plinia sp.), antes e após 30; 60; 90 e 120 dias de armazenamento. As barras representam o desvio-padrão.

\section{CONCLUSÕES}

1-Plinia trunciflora e Plinia jaboticaba são autocompatíveis, porém os polinizadores aumentam a frutificação.

2-Plinia cauliflora necessita de agentes polinizadores para frutificar, pois apresenta flores com maior distância estigma-anteras que as outras duas espécies, o que impede a autofecundação passiva.

3-A adição de ácido bórico no meio de cultura aumenta a germinação in vitro de pólen de jabuticabeira. horas da antese.

4-A viabilidade do pólen é máxima após seis

5-É possível a conservação do pólen de jabuticabeira por até 90 dias em congelador $\left(-18^{\circ} \mathrm{C}\right)$, desde que apresente alta germinação inicial (maior que $80 \%$ ).

\section{REFERÊNCIAS}

ALVES, J.E.; FREITAS, B.M. Requerimentos de polinização da goiabeira. Ciência Rural, Santa Maria, v.37, n.5, p.1281-1286, 2007.

APEL, M.A.; SOBRAL, M.; ZUANAZZI, J.A.; HENRIQUES, A.T. Essential oil composition of four Plinia species (Myrtaceae). Flavour and Fragrance Journal, Chichester, v.21, p.565-567, 2006.

BEARDSELL, D.V.; O'BRIEN, S.P.; WILLIAMS, E.G.; KNOX, R.B.; CALDER, D.M. Reproductive biology of Australian Myrtaceae. Australian Journal of Botany, Melbourne, v.41, p.511-526, 1993.

CRUZ, C.D. Programa genes: estatística experimental e matrizes. Viçosa: UFV, 2006. 285p.

DEGENHARDT, J.; ORTH, A.I.; GUERRA, M.P.; DUCROQUET, J.P.; NODARI, R.O. Morfologia floral da goiabeira serrana (Feijoa sellowiana) e suas implicações na polinização. Revista Brasileira de Fruticultura, Jaboticabal, v.23, p.718-721, 2001.

FARIA, F.S.; STEHMANN, J.R. Biologia reprodutiva de Passiflora capsularis L. e P. pohlii Mast. (Decaloba, Passifloraceae). Acta Botanica Brasilica, Porto Alegre, v.24, p.262-269, 2010. 
FERREIRA, K.; TORRES, G.A.; CARVALHO, I.V.; DAVIDE, L.C. Abnormal meiotic bahavior in three species of Crotalaria. Pesquisa Agropecuária Brasileira, Brasília, v.44, p.1641-1646, 2009.

FRANZON, R.C. Propagação vegetativa e modo de reprodução da pitangueira (Eugenia uniflora L.). 2008. 100 f. Tese (Doutorado em Agronomia) - Faculdade de Agronomia Eliseu Maciel, Universidade Federal de Pelotas, Pelotas, 2008.

FRANZON, R.C.; CASTRO, C.M.; RASEIRA, M.C.B. Variabilidade genética em populações de pitangueira oriundas de autopolinização e polinização livre, acessada por AFLP. Revista Brasileira de Fruticultura, Jaboticabal, v.32, p.240-250, 2010.

FRANZON, R.C.; RASEIRA, M.do C.B. Germinação in vitro e armazenamento do pólen de Eugenia involucrata DC (Myrtaceae). Revista Brasileira de Fruticultura, Jaboticabal, v.28, p.18-20, 2006.

FRANZON, R.C.; RASEIRA, M.do.C.B.; WAGNER JR., A. Testes de germinação in vitro e armazenamento de pólen de pitangueira (Eugenia uniflora L.). Acta Scientiarum, Maringá, v.29, p.251-255, 2007.

GOMES, P.R.; RASEIRA, M.C.B.; BAUDET, L.L.; PESKE, S.T. Armazenamento do grão de pólen de cebola (Allium cepa L.). Revista Brasileira de Sementes, Brasília, v.25, p.14-17, 2003.
KODAD, O.; COMPANY, R.S.; SÁNCHEZ, A.; OLIVEIRA, M.M. The expression of self-compatibility in almond may not only be due to the presence of the $S f$ allele. Journal of the American Society for Horticultural Science, Alexandria, v.134, p.221227,2009

LEE, C.L.; BÜNEMANN, G.; HERMANN, S. Long-term storage of plum pollen. Gartenbauwissenschaft, Berlin, v.46, p.69-72, 1981.

MALERBO-SOUZA, D.T.; NOGUEIRA-COUTO, R.H.; TOLEDO, V.A.A. Abelhas visitantes nas flores da jabuticabeira (Myrciaria cauliflora Berg) e produção de frutos. Acta Scientiarum, Maringá, v.26, p.1-4. 2004

MATTOS, J.L.R. Frutíferas nativas do Brasil: jaboticabeiras. Porto Alegre: Nobel, 1983. 92p.

MAUÉS, M.M.; COUTURIER, G. Biologia floral e fenologia reprodutiva do camu-camu (Myrciaria dubia (H.B.K.) McVaugh, Myrtaceae) no Estado Pará, Brasil. Revista Brasileira de Botânica, São Paulo, v.25, p.441-448, 2002.

SILVA, A.L.G.; PINHEIRO, M.C.B. Biologia floral e da polinização de quatro espécies de Eugenia L. (Myrtaceae). Acta Botanica Brasilica, Porto Alegre, v.21, p.235-247, 2007.

TEIXEIRA, L.N.; STRINGHETA, P.C.; OLIVEIRA, F.A. Comparação de métodos para quantificação de antocianinas. Revista Ceres, Viçosa, MG, v.55, p.297-304, 2008. 